\title{
Vacuum-assisted closure as a treatment modality for infections after cardiac surgery
}

\author{
Heyman Luckraz, FRCS \\ Fiona Murphy, $\mathrm{RGN}^{\mathrm{a}}$ \\ Steve Bryant, $\mathrm{SA}^{\mathrm{a}}$ \\ Susan C. Charman, $\mathrm{MSc}^{\mathrm{b}}$ \\ Andrew J. Ritchie, FRCS ${ }^{\mathrm{a}}$
}

From the Cardiothoracic Surgical Unit, Papworth Hospital, Papworth, Everard, ${ }^{\text {a }}$ and MRC Biostatistics Unit, Cambridge, ${ }^{\mathrm{b}}$ United Kingdom.

There is no conflict of interest with the company, KCI Medical Ltd, Whitney, United Kingdom, the manufacturer of the VAC pump and dressings used for the application of VAC. No financial or other benefits have been derived from the company by reporting our experience with topical negative pressure application.

Received for publication Dec 18, 2001; revisions requested Feb 18, 2002; revisions received March 20, 2002; accepted for publication March 29, 2002.

Address for reprints: Heyman Luckraz, FRCS, Cardiothoracic Specialist Registrar Papworth Hospital, Papworth Everard, Cambridge CB3 8RE, United Kingdom (Email: HeymanLuckraz@aol.com).

J Thorac Cardiovasc Surg 2003;125:301-5

Copyright (C) 2003 by The American Association for Thoracic Surgery

0022-5223/2003\$30.00+0

doi: $10.1067 / \mathrm{mtc} .2003 .74$
Objective: Wound infections after cardiac surgery carry high morbidity and mortality. A plethora of management strategies have been used to treat such infections. We assessed the impact of vacuum-assisted closure on the management of sternal wound infections in terms of wound healing, duration of vacuum-assisted closure, and cost of treatment.

Methods: Between November 1998 and June 2001, a total of 27 mediastinal infections were managed with vacuum-assisted closure. Group A $(\mathrm{n}=14)$ had vacuum-assisted closure as the final treatment modality, whereas in group B ( $\mathrm{n}=$ 13) vacuum-assisted closure was followed by either a myocutaneous flap $(n=8)$ or primary $(\mathrm{n}=5)$ wound closure. The choice of additional treatment modality was based on wound size.

Results: In group A, 4 patients died and a satisfactorily healed scar was achieved in $64 \%$ of cases. Median durations of vacuum-assisted closure and hospital stay in group A were 13.5 days (interquartile range 8.8-32.2 days) and 20 days (interquartile range 16.7-25.2 days), respectively. Mortality was $7.7 \%$ in group B, with a treatment failure rate of $15 \%$. Median duration of vacuum-assisted closure in group B was 8 days (interquartile range 5.5-18 days), and median hospital stay was 29 days (interquartile range 25.8-38.2 days). During the year before institution of vacuum-assisted closure, poststernotomy infection $(\mathrm{n}=13)$ was managed with rewiring and closed irrigation system. Treatment during this year failed in $30.7 \%$ of cases $(n=4 / 13)$, and mortality was also $30.7 \%$. The total cost (hospitalization and treatment) per patient for vacuum-assisted closure was $\$ 16,400$, compared with $\$ 20,000$ for the closed irrigation system treatment.

Conclusion: Vacuum-assisted closure, used alone or before other surgical treatment strategies, is an acceptable treatment modality for infections in cardiac surgery with reasonable morbidity, mortality, and cost.

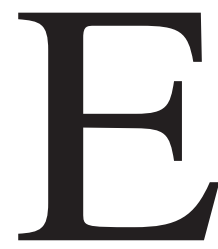

ven a century after the initial description of the median sternotomy approach to the heart, ${ }^{1}$ there is still no consensus regarding the treatment of poststernotomy mediastinitis. Fortunately, this is a rare complication, albeit one that carries high morbidity and mortality. ${ }^{2}$ Previously described management strategies for poststernotomy mediastinitis include the following in varying combinations: antibiotic therapy, wound incision and drainage, débridement, rewiring, closed irrigation, packing, delayed closure, and omental and myocutaneous flap reconstruction. ${ }^{3} \mathrm{~A}$ newly emerging treatment that has been added to this eclectic approach involves the use of vacuum-assisted closure (VAC), ${ }^{4}$ which has been described in only a handful of patients. ${ }^{4-6}$ We contribute to this literature by describing our experience with VAC in a series of 27 patients with poststernotomy mediastinitis. 


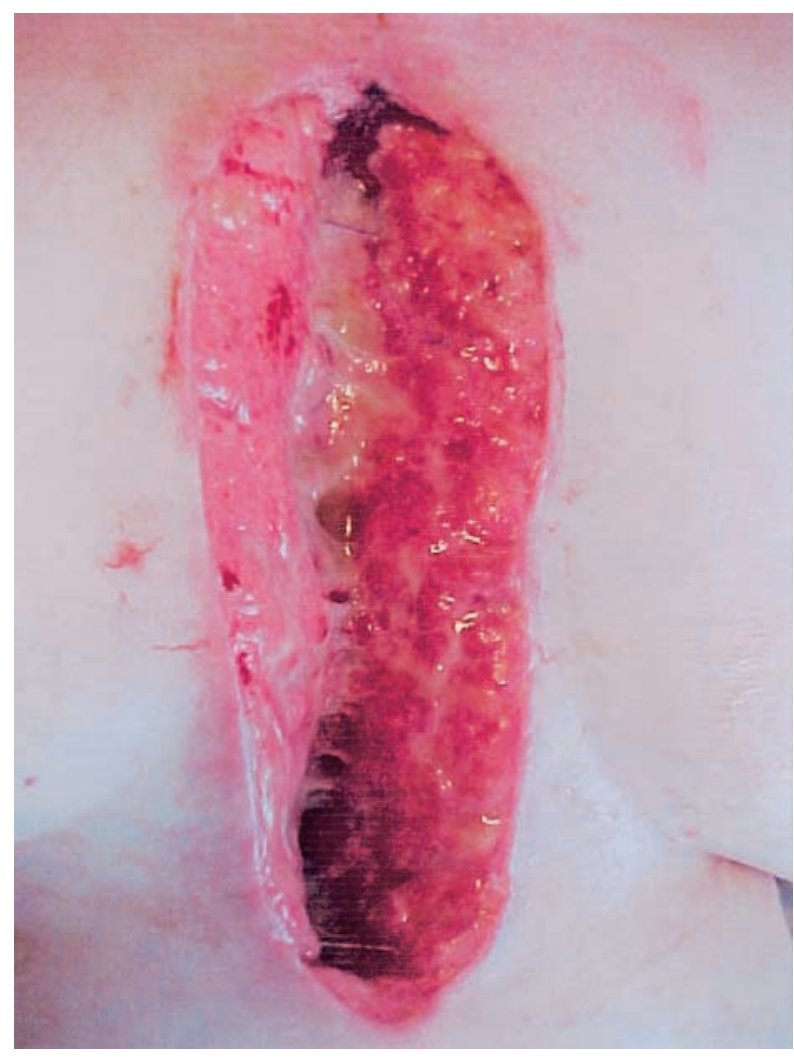

Figure 1. Sternal wound of 39-year old woman who underwent successful pulmonary thromboendarterectomy but developed poststernotomy mediastinitis.

\section{TABLE 1. Preoperative patient data}

\begin{tabular}{lcc}
\hline & Group A & Group B \\
\hline Age (y, mean \pm SD) & $65.6 \pm 12.3$ & $67.2 \pm 11.8$ \\
Body mass index $\left(\mathrm{kg} / \mathrm{m}^{2}\right.$, mean $\left.\pm \mathrm{SD}\right)$ & $30.9 \pm 3.7$ & $31.8 \pm 5.8$ \\
Male (\%) & $57 \%$ & $75 \%$ \\
Diabetes (\%) & $21 \%$ & $17 \%$ \\
Resternotomy (\%) & $7 \%$ & $17 \%$ \\
Elective surgery (\%) & $93 \%$ & $92 \%$ \\
Left internal thoracic artery (\%) & $86 \%$ & $67 \%$ \\
Bilateral internal thoracic arteries & $0 \%$ & $17 \%$ \\
Impaired left ventricular function (\%) & $36 \%$ & $58 \%$ \\
\hline
\end{tabular}

\section{Methods}

Between November 1998 and June 2001, a total of 27 out of 491 (0.05) patients who underwent cardiac surgery through a median sternotomy by a specific surgeon (A.J.R.) acquired sternal wound infections that were treated with the VAC technique (KCI Medical Ltd, Whitney, United Kingdom) either as definitive therapy (group A) or followed by a second procedure (group B). Initially, the intended treatment was VAC only. In 8 cases, however, the wound defect was quite large, and use of VAC alone for healing would have meant a much longer hospitalization. These patients therefore underwent myocutaneous flap closure, because the wound was "clean" and granulating after VAC application. Similarly, 5 patients underwent direct wound closure after VAC because this facilitated their discharge from the hospital.

Sternal wound infection was defined by positive results of microbial culture, persistent pyrexia in the setting of neutrophilia, or clinical evidence of sepsis. Antibiotic therapy was selected according to the sensitivity of the organism and the clinical response of the patient.

\section{Statistics}

Data are expressed as mean $\pm \mathrm{SD}$, as median with interquartile range, or as percentage of patients.

\section{Results}

Wound infections developed in patients undergoing coronary artery bypass grafting either alone $(\mathrm{n}=17)$ or in combination with aortic valve replacement $(n=6)$. In the remaining patients the initial surgical procedures were aortic valve replacement $(\mathrm{n}=2)$, pulmonary thromboendarterectomy $(\mathrm{n}=1)$, and transplantation $(\mathrm{n}=1)$. In 18 cases (66\%), VAC application was preceded by sternal wound débridement (group $\mathrm{A} \mathrm{n}=8$, group $\mathrm{B} \mathrm{n}=10$ ).

In group A, $21 \%$ of the patients had diabetes, and left internal thoracic artery was used in $86 \%$ of the cases. Mean body mass index was $30.9 \pm 3.7 \mathrm{~kg} / \mathrm{m}^{2}$. None of the patients in group A were receiving immunosuppressive therapy. A single infectious agent was isolated in $62 \%$ of cases. Methicillin-resistant Staphylococcus aureus was cultured in 3 patients (21\%) in group A, either alone or along with other bacteria. Infection was diagnosed at a median of 7.5 days (interquartile range 5.8-12.8 days) after the operation (incubation period). The duration of the VAC treatment was a median of 13.5 days (interquartile range 8.832.2 days). A healed scar was achieved in $76 \%$ of cases, but because of in-hospital deaths among these patients (not related to the wound problem), overall only $64 \%$ of patients survived with a satisfactorily healed scar. Of the remainder, 1 patient had a chronic persistent discharge from the sternal wound despite other therapy and a further 2 patients died in the hospital with multiorgan failure (total death rate 28.6\%). Two patients were discharged home with a battery-powered mini VAC. They were followed up in the outpatient department. The median hospital stay was 20 days (interquartile range 16.7-25.2 days), excluding the 4 patients who died and the 4 patients who were transferred to another hospital for convalescence. The median follow-up for group A patients was 4 months (interquartile range 3-9.2 months). No further sternal complications were encountered at followup.

Group B had methicillin-resistant Staphylococcus aureus cultured in 5 cases (38\%). Among the patients in group B, $17 \%$ had diabetes, $83 \%$ had internal thoracic artery harvested (17\% bilaterally), mean body mass index was $31.8 \pm$ $5.8 \mathrm{~kg} / \mathrm{m}^{2}$, and immunosuppressive therapy was used in 1 


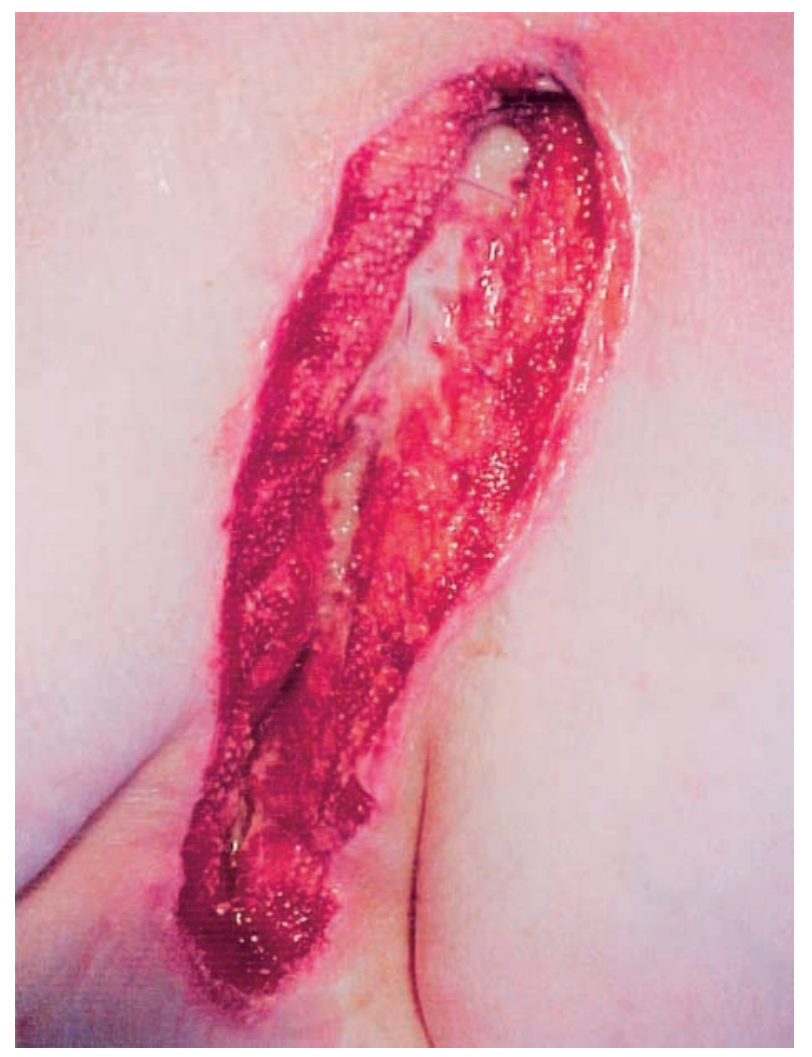

Figure 2. Same patient after 48 hours of VAC applied to wound. Note healthy granulation tissue.

case (Tables 1 and 2). Infection was diagnosed at a median of 9 days (interquartile range 7-15 days) after the operation, and duration of VAC treatment was a median of 8 days (interquartile range 5.5-18 days). A healed, stable sternum was achieved in 10 cases, with treatment failure in 2 cases and death in another. The median hospital stay was 29 days (interquartile range 25.8-38.2 days), excluding the 2 patients transferred to another hospital and the 1 who died. The median follow-up at 8 months (interquartile range 4.5-18.5 months) did not reveal any problems in those with a stable, healed sternum at hospital discharge. Overall (in both groups A and B), 70\% of the patients left the hospital with a satisfactorily healed scar.

Figures 1 through 3 illustrate the changes in a wound with poststernotomy mediastinitis in a patient who underwent pulmonary thromboendarterectomy after use of the VAC technique.

Before VAC insertion, the surgeon's preferred method of treatment for poststernotomy mediastinitis was sternal débridement and rewiring, followed by closed irrigation with rifampin antibiotic solution (INN: rifampicin). This was used in 13 patients during the 1-year period before VAC use commenced. The infection rate for that year was $0.04 \%$ $(\mathrm{n}=13 / 310)$. The treatment failure rate was $30.7 \%(\mathrm{n}=$

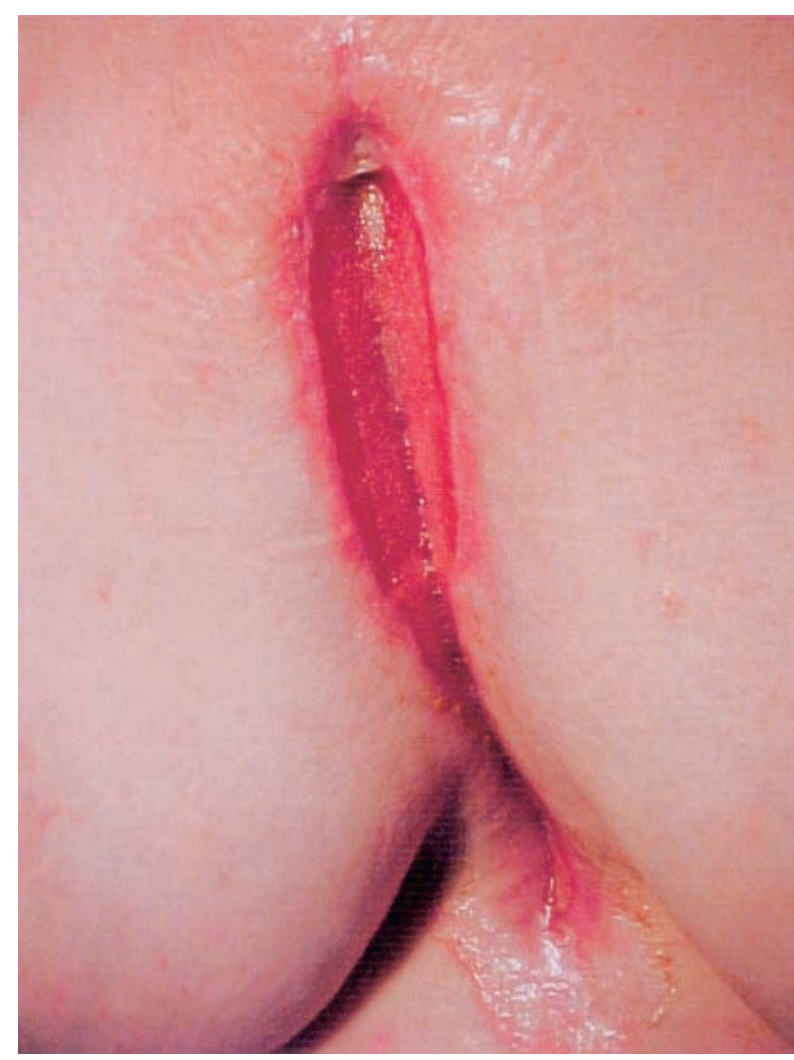

Figure 3. Sternal wound of same patient after VAC application for 2 weeks. Wound is almost completely healed by secondary intention with stable sternum.

4/13), necessitating further interventions. In 2 of these patients, further débridement was carried out and reconstruction with a myocutaneous flap was performed to restore chest stability. Four patients died of poststernotomy mediastinitis during that period (30.7\%). Excluding the patients who died $(\mathrm{n}=4)$ and the patients who were transferred to another hospital $(\mathrm{n}=3)$, the median hospital stay was 35.5 days (29.7-45.7 days).

The overall cost per patient for the VAC treatment was $\$ 16,400$, as compared with $\$ 20,000$ for the sternal rewiring and closed irrigation treatment.

\section{Discussion}

Severe infections in cardiac surgery, although rare, ${ }^{2}$ continue to burden the health care delivery service in terms of morbidity, mortality, and demands on personnel and cost. ${ }^{7}$ Treatment is usually prolonged, involving multiple trips to the operating room and the need for general anesthesia.

VAC is an addition to the armamentarium in the management of severe wound infections, and it several advantages relative to previous treatment strategies. VAC was initially described by Davydov and colleagues ${ }^{8}$ and success- 
TABLE 2. Perioperative and postoperative patient data

\begin{tabular}{lcc}
\hline & Group A & Group B \\
\hline $\begin{array}{l}\text { Cardiopulmonary bypass time } \\
\text { (min, mean } \pm \text { SD) }\end{array}$ & $98 \pm 54$ & $96 \pm 70$ \\
$\begin{array}{l}\text { Blood transfusion (mL, } \\
\text { median and interquartile } \\
\quad \text { range) }\end{array}$ & $227(0-479)$ & $0(0-412)$ \\
$\begin{array}{l}\text { Postoperative bleeding (mL, } \\
\text { median and interquartile }\end{array}$ & $512(318-650)$ & $700(563-963)$ \\
$\quad$ range) & & \\
$\begin{array}{l}\text { Incubation time (d, median } \\
\text { and interquartile range) }\end{array}$ & $7.5(5.8-12.8)$ & $9(7-15)$ \\
$\begin{array}{l}\text { VAC duration (d, median and } \\
\text { interquartile range) }\end{array}$ & $13.5(8.8-32.2)$ & $8(5.5-18)$ \\
$\begin{array}{l}\text { Hospital stay* (d, median and } \\
\quad \text { interquartile range) }\end{array}$ & $20(16.7-25.2)$ & $29(25.8-38.2)$ \\
$\begin{array}{l}\text { Healed scar (\%) } \\
\text { Mortality (\%) } \\
\text { Follow-up (mo, median and } \\
\quad \text { interquartile range) }\end{array}$ & $64 \%$ & $77 \%$ \\
\hline
\end{tabular}

*Excluding deaths and transfers to other hospitals.

fully adapted for surgical wound management by Morykwas and associates. ${ }^{9}$

The technique for VAC application has been described previously. ${ }^{4,5}$ The mechanisms of action include an increase in local blood flow, reductions of tissue edema and bacterial colonization rates, removal of chronic wound fluid and necrotic tissue, wound closure, and prevention of wound dehydration by the occlusive dressing. ${ }^{10}$ Negative pressure has been shown to increase dermal blood flow provided that it does not exceed $200 \mathrm{~mm} \mathrm{Hg.}{ }^{10}$ This may be due to a direct mechanical effect of sucking blood through the blood vessels. Topical negative pressure reduces tissue edema by removal of the interstitial fluid. A fall in bacterial count has also been noted with the application of topical negative pressure ${ }^{11}$; this effect may represent direct microbial removal or may be secondary to improved local blood supply. The extraction of chronic wound fluid promotes healing by eliminating matrix metalloproteinases, which have been shown to suppress endothelial cell and fibroblast proliferation. ${ }^{12}$ Last but not least, topical negative pressure causes reverse tissue expansion and hence promotes wound closure, a concept referred to by pundits as "mechanical creep." 13

An additional benefit from the use of VAC in the patients described here was that the dressing changes were all performed without the need for general anesthesia (except when VAC was applied at time of initial wound débridement with the patient already under general anesthesia). Dressing changes were carried out every 48 hours at minimum, which reduced the workload of the attending medical staff. The negative-pressure regimen that was followed included continuous suction for the first 48 hours followed by an intermittent suction (cycles of 5 minutes on and 2 minutes off) thereafter at a negative pressure not exceeding 125 $\mathrm{mm} \mathrm{Hg}$. There is also the possibility of sending the patient home with a portable version of the device.

The patients described in this series had significant premorbid risk factors for wound complication, especially severe obesity, use of internal thoracic artery, and diabetes. We are limited in our efforts to deliver the best available care by achieving a balance with the use of internal thoracic arteries (survival and patency benefits) in patients with obesity, diabetes, and immunosuppression.

Overall, a $70 \%$ success rate (healed wound) was achieved with the use of VAC. This is highly significant in this group of patients, among whom morbidity and mortality are usually high. The overall cost per patient of the VAC system was nearly $\$ 4000$ cheaper than that associated with a closed irrigation system at our institution. This difference reflects the reduced costs in operating room time, intensive care stay, and hospital stay. In our series, the median hospital stays were 20 days for group A and 29 days for group $\mathrm{B}$, as compared with 35.5 days for the closed irrigation system patients. A similar trend is reflected in previously published data. ${ }^{6}$ In that series, patients stayed a median of 40.5 days after the initiation of therapy for poststernotomy mediastinitis, which was closed drainage and irrigation.

It has now become clear that VAC is a highly reliable and reproducible treatment modality. We therefore intend to compare it with other strategies in a randomized, controlled study.

\section{Conclusion}

VAC treatment for severe wound infections in cardiac surgery has now become an established management modality. It has a reasonable success rate and is both reliable and reproducible. Its cost is acceptable when mortality, morbidity, demands on medical personnel, and end results are taken into consideration.

We are grateful to Ms F. Carey from the audit and clinical governance department for the data concerning the closed irrigation system group of patients and to Mrs R. Thornton, senior management accountant, for the costs of hospitalization and operating room time.

\section{References}

1. Milton H. Mediastinal surgery. Lancet. 1897;1:872-5.

2. Luckraz H, Treasure T. Infections in cardiac surgery. Curr Opin Surg Infect. 1996;4:1-4.

3. El Oakley RM, Wright JE. Post-operative mediastinitis: classification and management. Ann Thorac Surg. 1996;61:1030-6.

4. Obdeijn MC, de Lange MY, Lichtendahl DH, de Boer WJ. Vacuumassisted-closure in the treatment of poststernotomy mediastinitis. Ann Thorac Surg. 1999;68:2358-60.

5. Tang AT, Ohri SK, Haw PM. Novel application of vacuum assisted closure technique to the treatment of sternotomy wound infection. Eur J Cardiothorac Surg. 2000;17:482-4.

6. Catarino PA, Chamberlain MH, Wright NC, Black E, Campbell K, Robson D, et al. High-pressure suction drainage via a polyurethane 
foam in the management of poststernotomy mediastinitis. Ann Thorac Surg. 2000;70:1891-5.

7. Loop FD, Lytle BW, Cosgrove DM, Mahfood S, Meltery MC, Goormastic M, et al. Sternal wound complication after isolated coronary artery bypass grafting: early and late mortality, morbidity and cost of care. Ann Surg. 1990;49:179-87.

8. Davydov IA, Larichev AB, Abramov A. Wound healing after vacuum drainage. Khirurgiia Mosk. 1992;7:21-6.

9. Morykwas MJ, Argenta LC, Shelton-Brown EI, McGuirt W. Vacuum-assisted closure: a new method for wound control and treatment: animal studies and basic foundation. Ann Plast Surg. 1997; 38:553-62.
10. Banwell PE. Topical negative pressure therapy in wound care: a review of the development and use of sub-atmospheric pressures in the management of patients with different types of wound. $J$ Wound Care. 1999;8:79-84.

11. Fleischmann W, Becker U, Bischoff M, Hoekstra H. Vacuum sealing: indication, techniques and results. Eur J Orthop Surg Trauma. 1995; 5:37-40.

12. Bucalo B, Eaglstein WH, Falanga V. Inhibition of cell proliferation by chronic wound fluid. Wound Rep Regen. 1993;1:181-6.

13. Gibson T. The physical properties of the skin. In: Converse JM, editor. Reconstructive surgery. Vol 1. Philadelphia: WB Saunders; 1977. 